\title{
International Orthopaedics - instructions for authors, English expression, style and rules
}

\author{
${\text { Andrew } \text { Quaile }^{1} \cdot \text { Marius M. Scarlat }}^{2} \cdot$ Andreas F. Mavrogenis $^{3} \cdot$ Cyril Mauffrey $^{4}$
}

Published online: 31 October 2019

(C) SICOT aisbl 2019

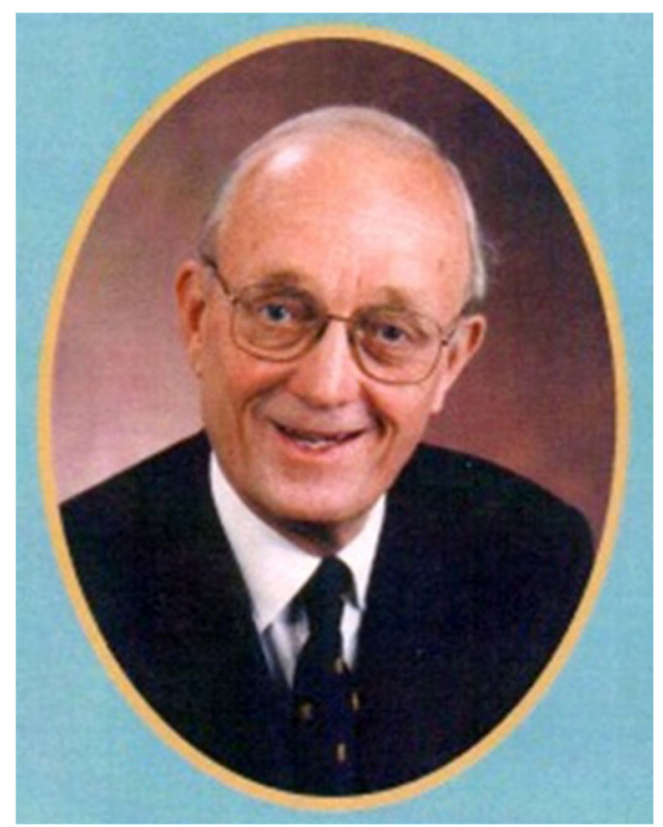

Fig. 1 Frank Horan $\uparrow$

All journals, of any standing, will have instructions for authors. This is to ensure the quality of published articles and to maintain the journals standards and reputation. This in turn

Marius M. Scarlat

mscarlat@gmail.com

1 Hampshire Clinic, Spineworks Basingstoke, Hampshire RG24 7AL, UK

2 Clinique St. Michel, Group ELSAN, Toulon, France

3 First Department of Orthopaedics, School of Medicine, National and Kapodistrian University of Athens, Athens, Greece

4 Department of Orthopedics Denver Health Medical Center, University of Colorado School of Medicine, Denver, CO, USA

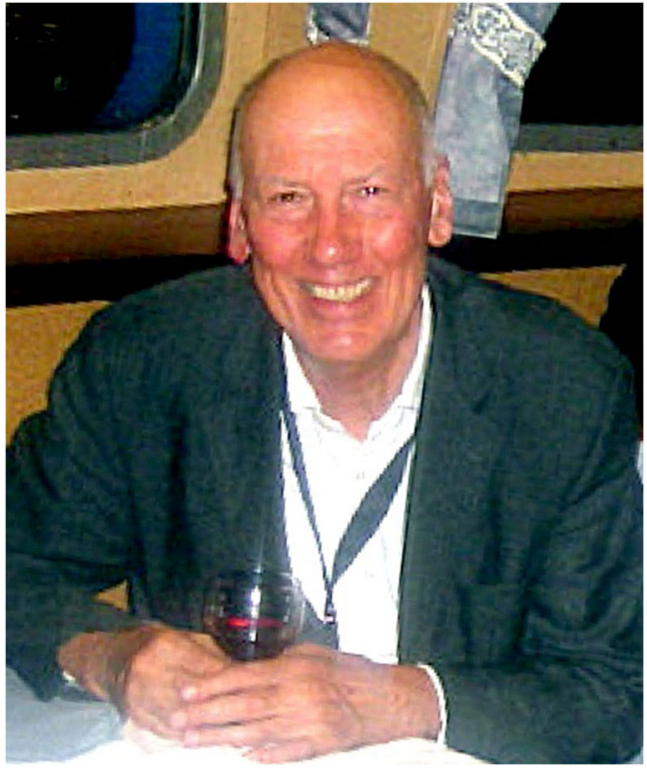

Fig. 2 James Scott

attracts papers from important authors, the whole process driving up citations as well as scientific and social impact. It is therefore necessary for a journal to have standards which are maintained. These standards should aim for a unified set of 'rules' including language, layout, title, references, keywords and so on. International Orthopaedics, as the mouth piece of SICOT, also has the role of education in orthopaedics in the developing world. This also extends to education in language and scientific expression. It is therefore very important for a paper to be expressed in terms the readership would understand but also in a way which completely educates the reader [1]. Journals will vary in the styles they adopt and therefore it is mandatory for authors to first read and to appreciate the target journal's style and to read the relevant journal's instructions for authors. Failure to do so risks the paper's rejection at the first stage. [2] 


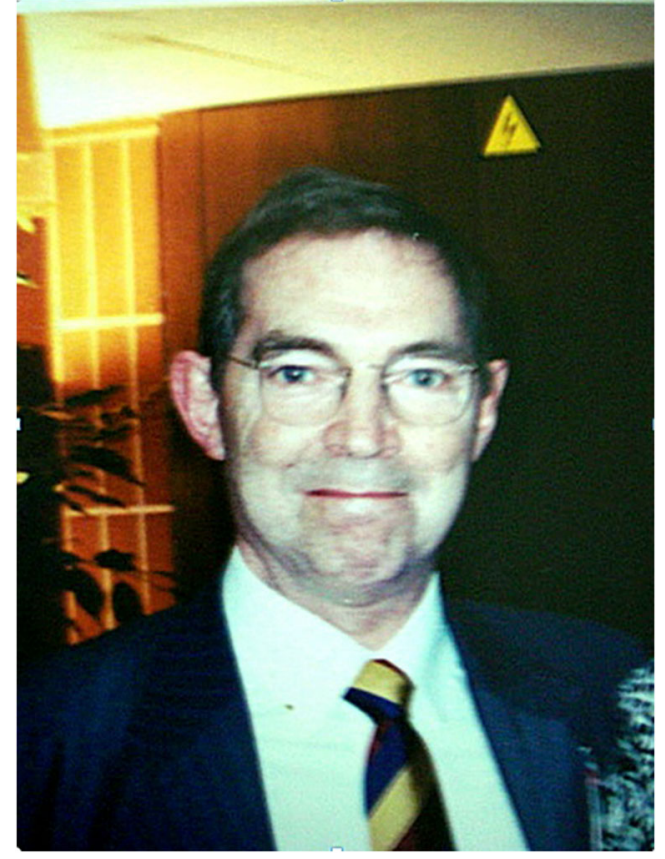

Fig. 3 Tony Hall

International Orthopaedics is published by Springer-Nature and there are instructions to authors available via the Springer website. There is a dedicate link www.editorialmanager.com/ inor/ which is available. International Orthopaedics, however, has some unique differences and are the reason for this editorial. The first issue of International Orthopaedics appeared in 1977 with Jacques Wagner as Editor and Robert Merle d'Aubigné as initiator. At first some articles were written in French. The Journal was published four times each year until 1992 when publication was increased to six issues through 2009 and then eight issues in 2010. Then in 2011 the journal was published every month. Alongside which are special issues

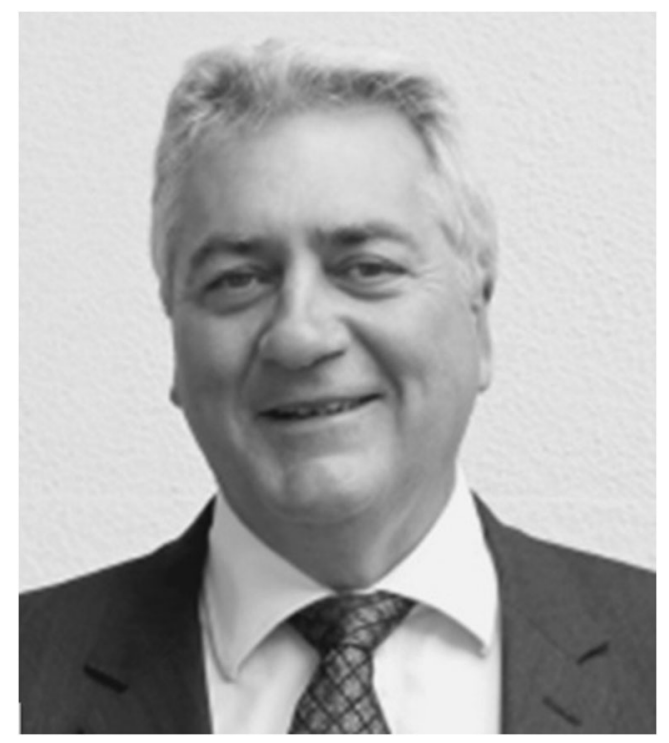

Fig. 4 Andrew Quaile which are now published once or twice a year. The responsibility for content and language editing commenced with Frank Horan $\dagger$ (Fig. 1) who became the English Associate Editor, a position that he held until 1997. James E. Scott (Fig. 2) replaced Frank Horan and held the English Associate Editor position from 1997 to 2002. Tony Hall (Fig. 3) became Associate English Editor in 2003, a position that he held until 2013. He was replaced by Andrew Quaile (Fig. 4), who is currently Deputy Editor in charge of the final layout of the journal and the quality of the language [3].

\section{Language}

The first and perhaps most obvious point is that International Orthopaedics is written in English. English is a language derived from many other languages such as Anglo-Saxon, Old Norse, Norman French, Latin and Greek. I make the point that historically for International Orthopaedics this is English and not American English and therefore there are differences of spelling. It is often said that we are separated by a common language! Examples would be the spelling of centre in English as opposed to center. Further examples would be tumour, favour, favourable, travelling, labelling, remodelling, fibres, manoeuvre, centimetre, millimetre, aetiology, oedema, foetal, behaviour etc.. These are very difficult to write in word as the program tries desperately to correct the spelling into a language other than English!! The style adopted is from New Hart's Rules, the handbook of style for authors and editors and the spelling from the Oxford English Dictionary.

English spelling which is becoming Americanised is the use of ise instead of ize in the same word, Americanized. We prefer the English version.

There are many phrases which are poor English rather than incorrect. We are aiming for articles, which make sense and therefore our preference would be to avoid some of the following:

This present paper - should be this paper or our paper if attempting to differentiate between a number of references. The paper isn't present anymore; it is past!

As well as - is used too often when a simple and will suffice most of the time.

Operated on - should be operated upon or indeed treated as we are talking about surgery anyway.

Effectiveness - efficacy is a better word.

Surgeries - operations or surgical procedures is much better English.

Control - is often used out of context when it is referring to follow-up.

Negative lists are frequently a problem; we did not find any fruit and vegetables should read, we did not find any fruit or vegetables.

Until now - change to date 
Like - meaning such as can usually become including. With the use of - can be utilising or more simply use.

The use of past tense is often incorrect for example, previous studies demonstrated should be previous studies have demonstrated.

With the purpose of providing should be to provide.

These are just some examples and the answer should be to have a native English speaker check the draft before submission, as services such as Google Translate or Word spell checker can be unreliable.

\section{Rules of writing}

There are some rules which most journals will follow and the rules for International Orthopaedics are no different. They include some of the following.

The title should be short and snappy to encourage interest. It should have no numbers, these should be written out in letters. There should be no acronyms or abbreviations as these should either be written longhand or not be included at all.

Numbers in the text up to and including ten should be written long hand, although avoiding numbers in brackets. In other words (10).

The text should be written clearly and fully explain the concept to be presented. It is often better to use simple language than overly complicated terminology. It is important that the same style is followed throughout. It is not unusual to have intraoperative spelt as one word in one sentence and intra-operative with a hyphen in another. Prefixes such as this may or may not be hyphenated but should be consistent throughout a paper. It is more common to use a hyphen with a prefix in English rather than in American English.

Hyphens are misunderstood and there is a dreadful tendency to invent new words by linking two individual words together. Hyphens are used to link words and parts of words. They are not as common today as they used to be, but there are three main cases where you should use them according to the Oxford English Dictionary:

In compound words hyphens are used to show that the component words have a combined meaning (e.g. a pickme-up, mother-in-law, good-hearted)

Hyphens can be used to join a prefix to another word, especially if the prefix ends in a vowel and the other word also begins with one (e.g. pre-eminent or co-own). This use is less common than it used to be, though, and one-word forms are becoming more usual (e.g. prearrange or cooperate). In International Orthopaedics pre-operative is preferred as is post-operative and posttraumatic is a dreadful word, posttraumatic being preferred.

To show word breaks hyphens can also be used to divide words that are not usually hyphenated. They show where a word is to be divided at the end of a line of writing. Always try to split the word in a sensible place, so that the first part does not mislead the reader; for example, hel-met not he-lmet; disabled not disa-bled.

\section{Keywords}

These must be provided and are key for search engines for a published paper. There should be four to six of these and they should ideally correspond to words that are referenced as MeSH (Medical Subject Headings) by the United States National Library of Medicine. Proper use of title and keywords enhance the visibility and reference search of the published paper and should be carefully addressed by the authors

\section{Units and quantities}

Recognised abbreviations such as $\mathrm{ml}, \%$ and so on are acceptable. When it comes to time there is often lack of consistency. Papers will discuss years, months, weeks, days and then turn to hrs. Min. and s. It is better to have them all written out for better understanding.

A set of rules is available on the Journal webpage along with the submission protocols: https://www.springer.com/ journal/264/submission-guidelines?IFA

\section{References}

1. Mavrogenis A, Quaile A, Scarlat M (2016) Attractive papers and accurate English. Int Orthop 40:649-651. https://doi.org/10.1007/ s00264-016-3172-9

2. Mauffrey C, Scarlat M (eds), Medical Writing and Research Methodology for the Orthopaedic Surgeon https://doi.org/10.1007/ 978-3-319-69350-7_2

3. Scarlat M, Hinsenkamp M, Quaile A, Pecina M (2016) International Orthopaedics is 40 years old! Int Orthop 40:1563-1569. https://doi. org/10.1007/s00264-016-3250_z

Publisher's note Springer Nature remains neutral with regard to jurisdictional claims in published maps and institutional affiliations. 